\title{
WATER LEVEL MONITORING ON TIBETAN LAKES BASED ON ICESAT AND ENVISAT DATA SERIES
}

\author{
H.W. Li, G. Qiao*, Y.J. Wu, Y.J. Cao, H. Mi \\ College of Surveying and Geo-Informatics, Tongji University, Siping Road 1239, Shanghai 200092, China -LiHW@ tongji.edu.cn; \\ qiaogang@tongji.edu.cn; 1633318@ tongji.edu.cn; yogacao@tongji.edu.cn; 2015mihuan@tongji.edu.cn.
}

\author{
Commission III, WG III/9
}

KEY WORDS: Satellite Altimetry, Tibet Plateau (TP), ICESat, Water Level, ENVISat

\begin{abstract}
:
Satellite altimetry technique is an effective method to monitor the water level of lakes in a wide range, especially in sparsely populated areas, such as the Tibet Plateau (TP). To provide high quality data for time-series change detection of lake water level, an automatic and efficient algorithm for lake water footprint (LWF) detection in a wide range is used. Based on ICESat GLA14 Release634 data and ENVISat GDR $1 \mathrm{~Hz}$ data, water level of 167 lakes were obtained from ICESat data series, and water level of 120 lakes were obtained from ENVISat data series. Among them, 67 lakes contained two data series. Mean standard deviation of all lakes is 0.088 meters (ICESat), 0.339 meters (ENVISat). Combination of multi-source altimetry data is helpful for us to get longer and more dense periods cover water level, study the lake level changes, manage water resources and understand the impacts of climate change better. In addition, the standard deviation of LWF elevation used to calculate the water level were analyzed by month. Based on lake data set for the TP from the 1960s, 2005, and 2014 in Scientific Data, it is found that the water level changes in the TP have a strong spatial correlation with the area changes.
\end{abstract}

\section{INTRODUCTION}

TP is the largest plateau in China and the highest plateau in the world, which is known as "The Roof of The World" and "Asian Water Tower" (Lu et al., 2005; Xu et al., 2008; Wilson et al., 2014). It is the densest area of lakes in China and even in the world. It is the birthplace of many rivers in East Asia, Southeast Asia and South Asia. Its environmental changes have a sensitive effect and a strong impact on global environment change. Since twenty-first century, in the environment of global warming, the Lakes on TP appeared obvious changes. Therefore, the analysis of the law of lake changes and the internal relationship with climate change has great significance for the protection of ecological balance, the prevention of natural disasters and the protection of the safety of drinking water.

The dynamic changes of lake water level relate to the meteorological elements closely such as rainfall, temperature, evaporation and humidity. Regular and accurate monitoring of lake water level changes is helpful for us to manage water resources and understand the impacts of climate change better. Lake water level information is usually obtained by continuous observation from hydrological stations. The water level information obtained in this way is continuous and highprecision. However, in the remote and sparsely populated areas like TP, most lakes have no hydrological stations, and it is difficult to obtain water level information of lakes in a large scale. In recent years, with the continuous improvement of satellite altimetry technology and its wide application in the ocean, it provides a new technical method to monitor the water level of inland lakes (Song et al., 2015). Some scholars have studied the change of lake water level on the part or the whole TP. Zhang et al. (2011) monitored water level dynamic changes of 74 lakes on TP during 2003-2009 by using ICESat data and water bodies extracted by MODIS images.
Phan et al. (2012) obtained the water level of 154 lakes on TP from 2003 to 2009 years by similar methods. However, due to the single altimetry data, both spatial coverage and temporal coverage are limited, most lakes on TP do not have altimetry data or have only a few months of water level data. It is difficult to obtain a long lake water level sequence. Tong et al. (2016) proposed a fusion method of multi-source altimetry data and applied it on Lake Vitoria.

\section{DATASET AND METHODOLOGY}

\subsection{Dataset}

In this study, all ICESat/GLA14 Release634 elevation data crossing the study area during 2003 to 2009 and ENVISat GDR $1 \mathrm{~Hz}$ data crossing the study area during 2002 to 2012 were obtained through the U.S. National Snow and Ice Data Center (NSIDC) and European Space Agency (ESA) Respectively. The lake data set for the TP from the 1960s, 2005, and 2014 published in Scientific Data was used as secondary data. (Wan et al.,2016)

\subsection{Data Processing}

The method of calculating lake water level by satellite altimetry is similar to the basic principle of calculation of sea water level. Based on the principle of satellite altimetry, the formula for calculating lake water level is as follows:

$$
\text { Elevation }_{\text {Measured }}=\text { Sat }_{\text {Alt }}-H_{A l t}-\text { Corrections }
$$

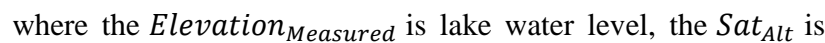
the ellipsoidal height of satellite centroid, the $H_{A l t}$ is the distance measured by the altimeter, the Corrections is the error correction. 
Compared with the open ocean, the area of land lakes is quite small, so the effect of ocean tide and reverse pressure is limited. Therefore, calculating lake error correction is different from ocean error correction. The specific error model is as follows:

$$
\text { Corrections }=\text { Cen }+ \text { Wet }+ \text { Iono }+ \text { Dry }+ \text { Sol }+ \text { Pol }
$$

where the Cen is the centroid correction, the Wet is the wet convection correction, the Iono is the ionosphere correction, the Dry is the dry troposphere correction, the Sol is the solid tide correction, and the $\mathrm{Pol}$ is the pole tide correction.

Take ICESat for example the elevations are referenced to the Topex/Poseidon ellipsoid and EGM96 Geoid. We convert them (Elevation Measured $_{\text {) to the WGS84 ellipsoid elevations }}$ (Elevation), using the Eq.1, in order to compare with fieldmeasured elevations, as WGS84 is normally used in all GPS units.

Elevation $=$ Elevation $_{\text {Measured }}-$ Geoid -0.7

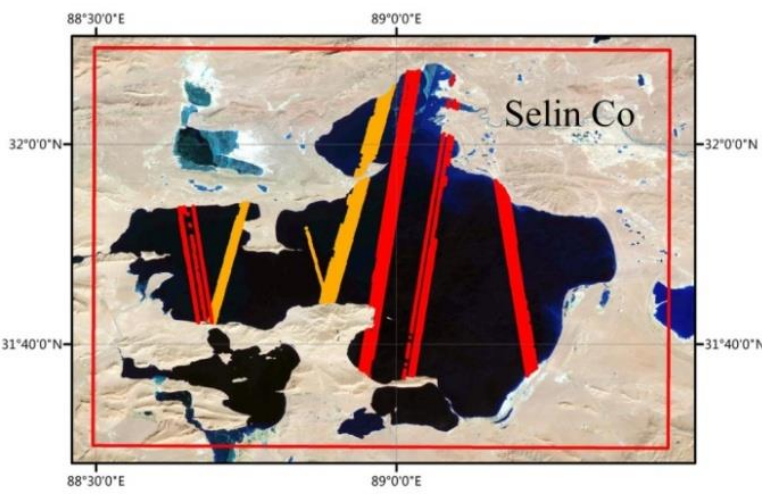

(a) where the Elevation $_{\text {Measured }}$ and Geoid are directly provided from the ICESat data, and the $0.7 \mathrm{~m}$ is the offset from Topex/Poseidon ellipsoid to WGS84 ellipsoid.

The calculated elevation values are unified to the WGS 84 ellipsoid, and the linear clustering method is used to select the LWFs. Based on ICESat GLA14 Release634 data and ENVISat GDR $1 \mathrm{~Hz}$ data, only elevation values were taken as features of an algorithm for LWF detection, and the time of the data, latitude \& longitude and track number were used as auxiliary. Similar to the K-medoids method, it has its basis only in the Hdifference between data points. Finally, ICESat and ENVISat water level sequences are obtained by calculating the mean values.

By the method of this paper, we can not only filter the data within the lake, but also remove the gross errors. As shown in the Figure 1., put LWFs of Selin Co into Latitude-Height coordinate system, We can visually see that the LWFs detection work is well done.



(b)

Figure 1. Result of LWFs classification for Selin Co

Because the water level results of ICESat data are more precision, in this paper, we use the same time water level to calculate the system error between ENVISat and ICESat. Then ENVISat results are corrected to the ICESat results. Finally we get longer and more dense periods cover water level.

\section{RESULTS AND ANALYSIS}

Type Water level of 167 lakes were obtained from ICESat data series, and water level of 120 lakes were obtained from ENVISat data series. Among them, 67 lakes contained two data series. Among them, Nam Co, Selin Co and YamdrokTso are selected as representative lakes. Lake water level sequences of three lakes are shown in Figure 2. and Figure 3. (a)(b)(c).

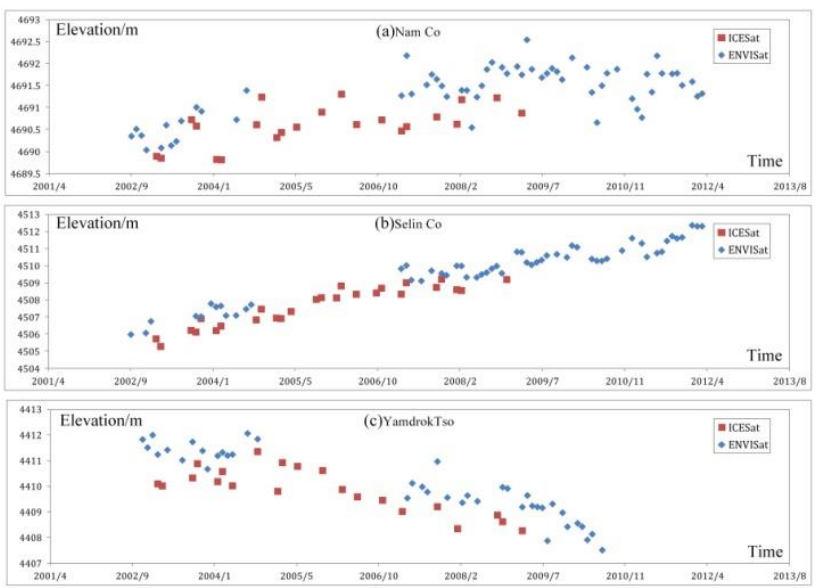

Figure 2. Typical lake water level sequences with the system errors (a) Nam Co; (b) Selin Co; (c) YamdrokTso. 


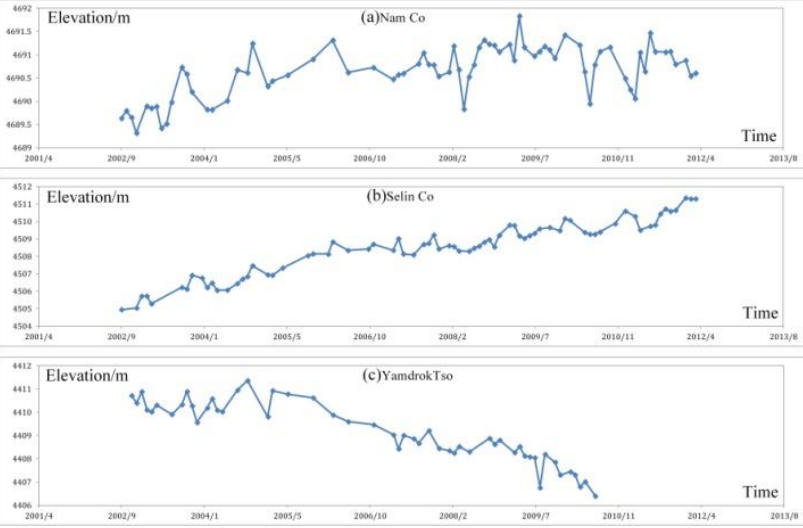

Figure 3. Typical lake water level sequences with the system errors removed (a) Nam Co; (b) Selin Co; (c) YamdrokTso.
As it shown in Figure 2. and Figure 3., from 2002 to 2012, Nam Co and Selin Co have a very obvious rising trend, at the same period, YamdrokTso has a downward trend. The mean lake level change rates are $0.12,0.64$ and $-0.54 \mathrm{~m} /$ year, respectively.

Compared to a single altimetry data, the water level has a longer range of time series and a more dense monthly data coverage, which can help us study the law of water level changes in depth. Figure 4. shows the lake water level changes on TP from 2002 to 2012. Most lake water level of lakes on TP showed a clear upward trend during the period, but some lakes in the Yarlung Zangbo River Basin show a downward trend. The annual average precipitation is less in most place of TP except the southwestern part of China, so precipitation is not a cause of the general rise of lake water level. In summary, lake levels in the TP are mostly increasing by integrating glacier melt runoff from the glaciers throughout their basins and this generally confirms the accelerated glacier melting throughout most of the Plateau.

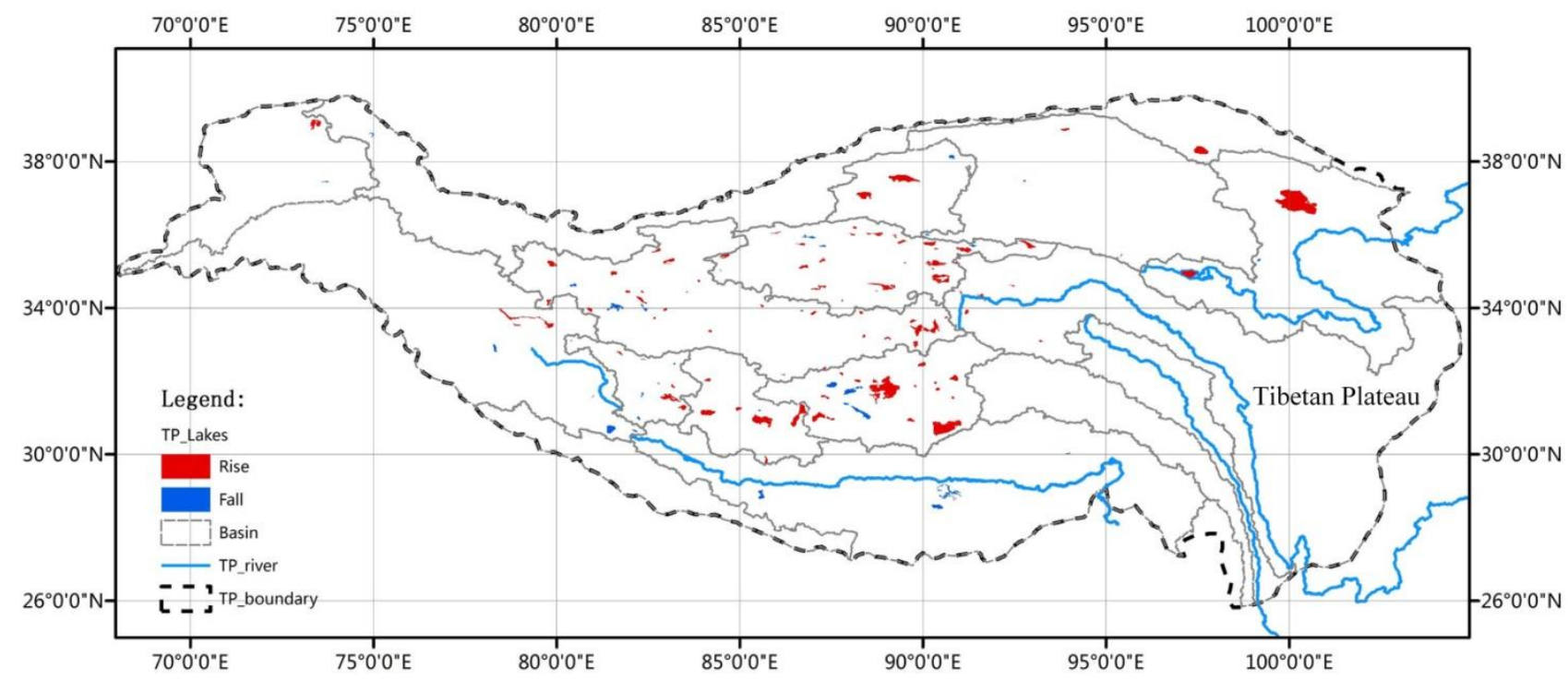

Figure 4. Lake water level changes in the Tibetan Plateau from 2002 to 2012

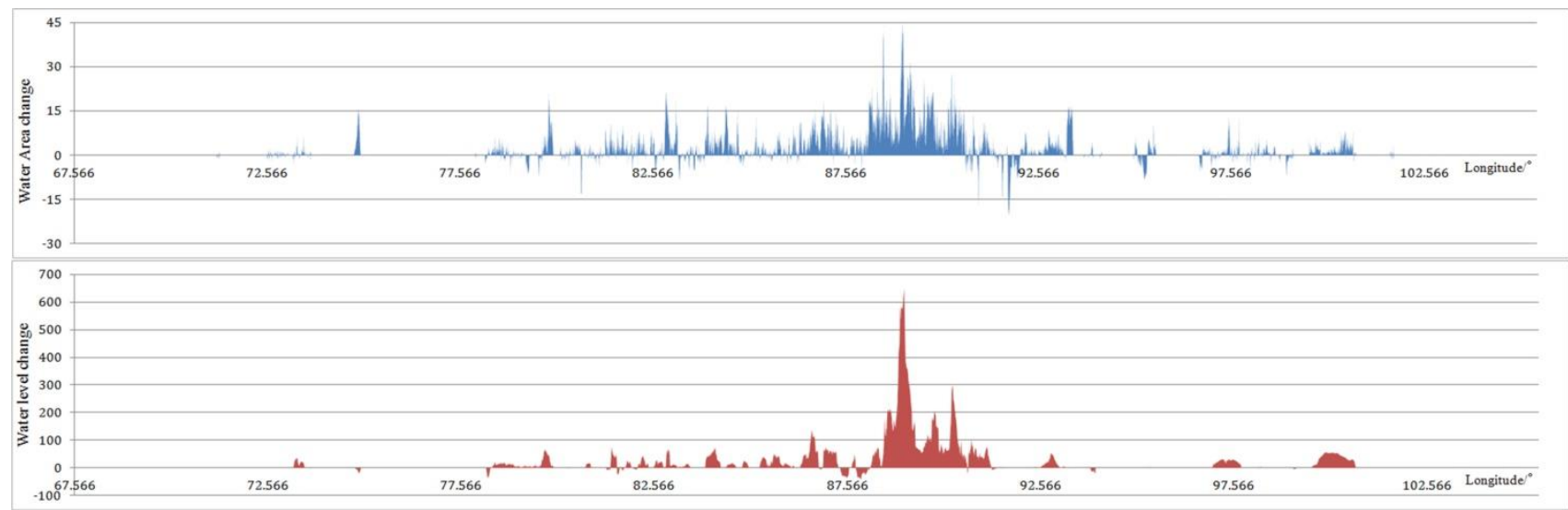

Figure 4. Statistical histogram of lake area and water level change from 2002 to 2012 on TP in longitude 


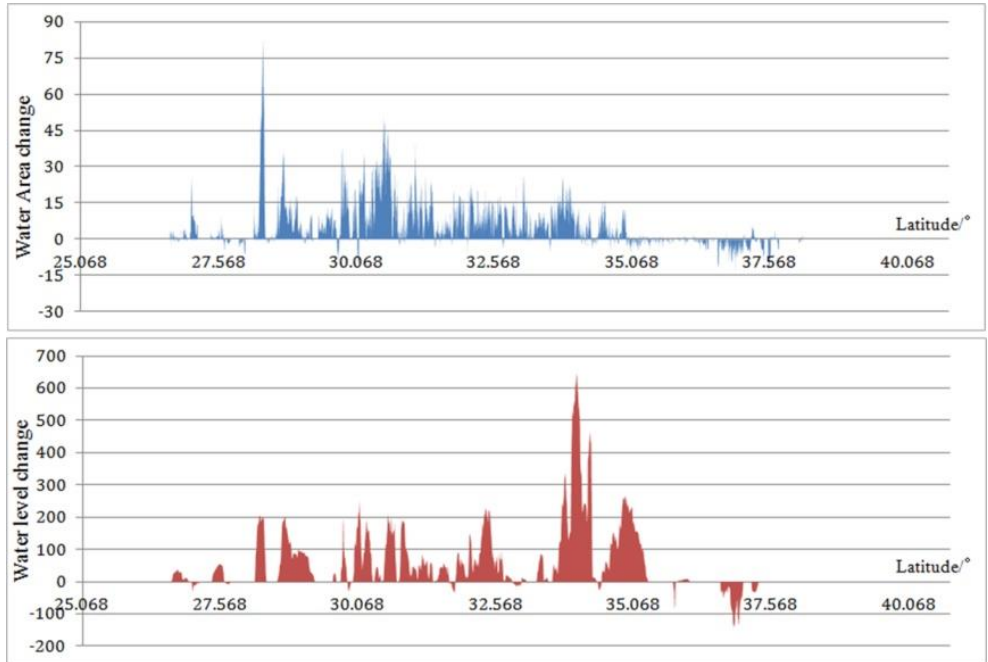

Figure 5. Statistical histogram of lake area and water level change from 2002 to 2012 on TP in latitude

Combine with the image dataset of lakes on TP, we do a statistical analysis on the change of lake area and water level in longitude direction and latitude direction, the results were shown in Figure 4. and Figure 5.. We can find that In the Inner Basin, lake change is most obvious. The change of the lake area on TP had a good spatial correlation with the water level changes covered by ICESat or ENVISat data in both longitude and latitude direction.

\begin{tabular}{|c|cccccccccccc|}
\hline Month & 1 & 2 & 3 & 4 & 5 & 6 & 7 & 8 & 9 & 10 & 11 & 12 \\
\hline ICESat & $\tilde{1}$ & 0.081 & 0.097 & 0.138 & 0.087 & 0.073 & $\tilde{3}$ & $\tilde{3}$ & 0.069 & 0.082 & 0.094 & 0.067 \\
ENVISat & 0.276 & 0.264 & 0.288 & 0.357 & 0.399 & 0.401 & 0.386 & 0.386 & 0.386 & 0.351 & 0.330 & 0.325 \\
\hline
\end{tabular}

Table 1. Mean standard deviation of the TP LWFs for every month

Through this paper's method, the mean standard deviation of the TP LWFs is obtained, the mean standard deviation of ICESat is about 0.088 meters, and the average standard deviation of ENVISat is about 0.339 meters. We can also see that the accuracy of ICESat is significantly higher than ENVISat. The mean standard deviation of LWFs per month is counted, they were shown in Table 1.. In TP, ICESat has data in February, March, April, May, June, September, October, November, December. ENVISat has data in TP every month. The mean standard deviation of ICESat in every month is very close, which may be related to the high accuracy of the altimetry. The monthly mean standard deviation of ENVISat in April to September is bigger than in October to March. In June the mean monthly standard deviation is the biggest, in January the mean monthly standard deviation is the smallest. The main reason may be that in October to the following year March, the TP temperature is low, most lake are frozen, so the measurement results are better. From April to September, the average temperature is relatively high, the lakes are not frozen, the water level fluctuates greatly, and some areas are in rainy season, so the standard deviation is larger.

\section{CONCLUSION}

According to the above analysis of altimetry data of TP lakes, the following conclusions can be drawn:

(1)The combination of multi-source altimetry datasets helps to obtain a more intensive water level sequence for a longer period of time. It facilitates the research of variation laws of lake water level. In addition, it can manage the water resources and understand the impact of climate change better.

(2)The lake water level of lakes on TP showed a clear upward trend from 2002 to 2012. However, the annual average precipitation is less in most place of TP except the southwestern part of China, so precipitation is not a cause of the general rise of lake water level. The rise of lake water level is closely related to the rise of temperature and melting of glaciers, permafrost and snow.

(3)From 2002 to 2012, the change of the lake area on TP had a good spatial correlation with the water level changes covered by ICESat or ENVISat data in both longitude and latitude direction.

(4)The data quality of lake altimetry on TP (LWFs elevation standard deviation) is closely related to the freezing of lakes, and the quality of altimetry data in the glacial month is obviously better than that in other months.

\section{ACKNOWLEDGEMENTS (OPTIONAL)}

In this paper all altimetry data were obtained through the U.S. National Snow and Ice Data Center (NSIDC) and European Space Agency (ESA), and lake data set for the TP from the 1960s, 2005, and 2014 published in Scientific Data was used as secondary data. Thanks!

This research was supported by the National Science Foundation of China (91547210, 41771471, 41201425), the National Key R esearch and Development Program of China (2017YFA0603102 ), and the Fundamental Research Funds for the Central Universit ies.

\section{REFERENCES}

Lu C., Yu G. and Xie G., 2005. "Tibetan plateau serves as a water tower," in 2005, . DOI: 10.1109/IGARSS. 1526498.

$\mathrm{Xu} \mathrm{X}$. et al., 2008. "World water tower: An atmospheric perspective," Geophysical Research Letters, vol. 35, (20). 
Wilson M. C. and Smith A. T., 2015. "The pika and the watershed: The impact of small mammal poisoning on the ecohydrology of the Qinghai-Tibetan Plateau," Ambio, vol. 44, (1), pp. 16-22.

Song C., Huang B. and Ke L., 2014. "Inter - annual changes of alpine inland lake water storage on the Tibetan Plateau: Detection and analysis by integrating satellite altimetry and optical imagery," Hydrological Processes, vol. 28, (4), pp. 24112418.

Zhu W., Jia S. and Lv A., 2014. "Monitoring the Fluctuation of Lake Qinghai Using Multi-Source Remote Sensing Data," Remote Sensing, vol. 6, (11), pp. 10457-10482.

Song C., Huang B. and Ke L., 2015. "Heterogeneous change patterns of water level for inland lakes in High Mountain Asia derived from multi - mission satellite altimetry," Hydrological Processes, vol. 29, (12), pp. 2769-2781.

Phan V. et al., 2017. "Assessing Orographic Variability in Glacial Thickness Changes at the Tibetan Plateau Using ICESat Laser Altimetry," Remote Sensing, vol. 9, (2), pp. 160.

Phan V. et al., 2012. "ICESat derived elevation changes of Tibetan lakes between 2003 and 2009," International Journal of Applied Earth Observation and Geoinformation, vol. 17, pp. 1222.

Tong X. et al., 2016. "Estimating water volume variations in Lake Victoria over the past 22 years using multi-mission altimetry and remotely sensed images," Remote Sensing of Environment, vol. 187, pp. 400-413.

Song C. et al., 2015. "Shifts in water-level variation of Namco in the central Tibetan Plateau from ICESat and CryoSat-2 altimetry and station observations," Science Bulletin, vol. 60, (14), pp. 1287-1297.

Zhang G. et al., 2011. "Monitoring lake level changes on the Tibetan Plateau using ICESat altimetry data (2003 - 2009)," Remote Sensing of Environment, vol. 115, (7), pp. 1733-1742.

Ablain M. et al., 2015. "Improved sea level record over the satellite altimetry era (1993-2010) from the Climate Change Initiative project," Ocean Science, vol. 11, (1), pp. 67-82.

Kouraev A. V. et al., 2007. "Observations of Lake Baikal ice from satellite altimetry and radiometry," Remote Sensing of Environment, vol. 108, (3), pp. 240-253.

Zheng J. et al., 2016. "Monitoring changes in the water volume of Hulun Lake by integrating satellite altimetry data and Landsat images between 1992 and 2010," Journal of Applied Remote Sensing, vol. 10, (1), pp. 16029.

Duan Z. and Bastiaanssen W., 2013. "Estimating water volume variations in lakes and reservoirs from four operational satellite altimetry databases and satellite imagery data," Remote Sensing of Environment, vol. 134, pp. 403-416. 